\title{
The comparison of oxaliplatin or irinotecan rechallenge treatment with regorafenib in the third-line treatment of metastatic colorectal cancer
}

\section{Metastatik kolorektal kanserin üçüncü basamak tedavisinde oksaliplatin veya irinotekan rechallenge tedavi ile regorafenib karşılaştırması}

\author{
Yakup Ergün, Öznur Bal, Mutlu Doğan, Gökhan Uçar, Merve Dirikoç, Yusuf Açıkgöz, Doğan Uncu \\ SBÜ Ankara Numune Eğitim ve Araştırma Hastanesi, T1bbi Onkoloji Bölümü, Ankara
}

Dergiye Ulaşma Tarihi:04.11.2018 Dergiye Kabul Tarihi:05.12.2018 Doi: 10.5505/aot.2019.83703

\section{ÖZET}

GİRIŞ ve AMAÇ: Bu çalışmada iki basamak standart tedavi almış metastatik kolorektal kanser (mKRK) tanılı hastalarda oksaliplatin ya da irinotekan bazlı rejimlerin yeniden verildiği (rechallenge) hastalar ile regorafenib alan hastaların gerçek yaşam verilerinin karşılaştırılması amaçlandı.

YÖNTEM ve GEREÇLER: Ocak 2010 ve Aralık 2017 tarihleri arasında merkezimizde mKRK tanısıyla takip edilen 427 hastanın verileri retrospektif olarak değerlendirilip, iki basamak stardart kemoterapi sonrası progresyon nedeniyle rechallenge kemoterapi (n: 40) veya regorafenib (n: 21) alan 61 hasta çalışmaya alındı.

BULGULAR: Medyan takip süresi 7.1 aydı (aralık; 2.2-41.6). Hiçbir hastamızda tam yanıt gözlenmez iken parsiyel yanit rechallenge grubunda $\% 17$, regorafenib grubunda ise $\% 5$ olarak bulundu $(\mathrm{p}=0.2)$. Rechallenge grubunda ortanca genel sağkalım (GSK) 9.6 ay (\%95 CI 7.3-13.3) iken regorafenib grubunda 7 ay (1.9-17) olup istatistiksel olarak fark yoktu (Hazard oranı [HR]: 1.05; \%95 Güven aralığ1 [GA] 0.5-2.1, p=0.9). Ortanca progresyonsuz sağkalım da (PSK) her iki grupta benzerdi (sırasıyla; 4.7 ay ve 3.1 ay, HR: 1.45 ; $95 \%$ GA 0.82 $2.5, \mathrm{p}=0.1$ ). Rechallenge grubundaki hastalar önceki tedavilerinde tedavisiz süre (TS) $<6$ ay ve $\geq 6$ ay olarak ayrıldığında TS $\geq 6$ ay olan grupta ortanca PSK (sırasıyla 6.7 ay ve 4 ay, $p=0.4$ ) ve GSK (10.3 ve 7.1 ay, $\mathrm{p}=0.1$ ) numerik olarak daha iyi olsa da bu fark istatistiksel olarak anlamlı değildi.

TARTIŞMA ve SONUÇ: Bulgularımıza göre rechallenge tedavi ile regorafenib benzer etkinliktedir. Bu verilere dayanarak kötü prognozlu olan bu hasta grubunda rechallenge tedavi üçüncü basamakta alternatif bir tedavi seçeneği veya önerilen tedaviler ile progrese olan hastalarda sonraki basamaklarda tercih edilebilecek bir rejim olabilir. Ancak hasta sayımızın azlığı ve çalışmamızın retrospektif olması nedeniyle bu konuda çok sayıda hasta içeren prospektif çalışmalara ihtiyaç vardır.

Anahtar Kelimeler: metastatik kolorektal kanser, üçüncü basamak tedavi, regorafenib, rechallenge, oksaliplatin, irinotekan

\section{ABSTRACT}

INTRODUCTION: In this study, we aimed to compare the results of regorafenib with those of oxaliplatin or irinotecan based rechallenge therapy as the third-line treatments for metastatic colorectal cancer (mCRC). METHODS: Between January 2010 and December 2017, data of 427 mCRC patients were evaluated retrospectively. Sixty one mCRC patients who received regorafenib (n: 21) or rechallenge therapy (n: 40) as third-line setting were included.

RESULTS: Median follow-up was 7.1 months (range; 2.2-41.6). While no complete response was observed in any of our patients, the partial response was $17 \%$ in the rechallenge group and $5 \%$ in the regorafenib group $(\mathrm{p}=0.2)$. In the Rechallenge group, the median OS was 9.6 months (95\% CI 7.3-13.3), while in the regorafenib group 7 months (1.9-17) there was no statistically significant difference (HR: 1.05 ; 95\% CI 0.5-2.1, $\mathrm{p}=0.9$ ). Median progression-free survival (PFS) was similar in both groups (4.7 and 3.1 months, HR: 1.45 ; 95\% CI 0.82 2.5, $\mathrm{p}=0.1)$. Although median PFS (6.7 months and 4 months, $\mathrm{p}=0.4)$ and OS $(10.3$ and 7.1 months, $\mathrm{p}=0.1)$ were numerically better in treatment free-interval (TFI) $\geq 6$ months group, this difference was not statistically significant.

DISCUSSION AND CONCLUSION: According to our findings, regorafenib with rechallenge treatment is similar activity. Based on these data, rechallenge therapy in this patient group with poor prognosis may be an alternative treatment option in the third step or a regimen that can be preferred in the next steps in the patients who are scheduled with the recommended treatments. However, due to the small number of our patients and the retrospective nature of our study, prospective randomized trials with large number of patients are needed in this area.

Keywords: metastatic colorectal cancer, third line treatments, regorafenib, rechallenge, oxaliplatin, irinotecan 


\section{GíRiș}

Son yirmi yıla kadar tek ajan 5-fluorourasil (5FU) ile metastatik kolorektal kanserde (mKRK) ortanca genel sağkalım (GSK) 12 ay civarındaydı. Son yirmi yılda onaylanan diğer kemoterapötik ve hedefe yönelik biyolojik ajanlar ile günümüzde ortanca GSK 3 yıla yaklaşmıştır (1). Günümüzde mKRK' in standart tedavisinde fluroprimidinler (5-FU, kapesitabin), irinotekan ve oksaliplatin olmak üzere üç ana kemoterapötik ajan ile anti vasküler büyüme faktörü (Anti-VEGF) ve anti epidermal büyüme faktörü reseptörü (AntiEFGR) olmak üzere iki hedefe yönelik biyolojik ajan grubu kullanılmaktadır (2-3). $\mathrm{Bu}$ ajanların kombinasyonları 2004 yılından beri genellikle siralı olarak kullanılmaktadır. FOLFOX (folinik asit (FA), 5-FU ve oksaliplatin) veya CAPOX (Kapesitabin ve oksaliplatin) ile tedaviye başlayanlarda ikinci basamakta FOLFIRI (FA, 5-FU ve irinotekan) verilir veya bu siranın tersi uygulanır (4).

İki basamak standart tedaviden sonra tek başına destek tedavisi ile ortanca GSK 4-6 ay civarındadır (5-6). Bu kötü prognoz nedeniyle iki basamak standart tedavi sonrasinda progrese olan hastalarda tedavi arayışları devam etmektedir. $\mathrm{Bu}$ hasta grubunda önerilen regorafenib, trifluridin/tipiracil (TAS-102) gibi tedavi seçenekleri ile ortanca GSK 7-8 ay civarındadır (7-9). Regorafenib; oral olarak kullanılan, tümör büyümesi ve anjiogenezde rol alan birçok reseptör tirozin kinazın (VEGF, FGF, PDGF, BRAF, KIT, RET) küçük moleküllü inhibitörüdür (10). mKRK'de regorafenibin etkinliği CORRECT (7) ve CONCUR (8) çalışmaları ile gösterildikten sonra standart tedaviyi tamamlayan hastalarda regorafenib yaygin olarak kullanılmaya başlanmıştır.

Rechallenge tedavi; tümörün dirençli olduğu bilinen tedavi rejiminin araya giren en az bir basamak tedaviden sonra tekrar verilmesi olarak tanımlanabilir. İki basamak tedaviden sonra progrese olan hastalarda sinırlı sayıdaki mevcut ajandan dolayı daha önce almış olduğu standart tedavilerin yeniden verilmesi bir seçenek olabilir. OPTIMOX (11) ve RE-OPEN (12) çalışmalarında oksaliplatinin yeniden kullanılmasıyla klinik fayda sağlanabileceği gösterilmiştir.
Bildiğimiz kadarıyla kemorefrakter mKRK'de hastalarda oksaliplatin ya da irinotekan bazl1 rejimlerle rechallenge tedavi ve regorafenibi karşılaştıran çalışma yoktur. Bu konuyla ilgili yapılan ilk çalışma olan retrospektif analizimizde; iki basamak standart kemoterapi almış kemorefrakter mKRK'li hastalarda FOLFOX +/- biyolojik ajan veya FOLFIRI +/- biyolojik ajan ile rechallenge tedavi uygulanan hastalar ile regorafenib alan hastaların gerçek yaşam verilerini karşılaştırmalı olarak değerlendirmeyi amaçladık.

\section{GEREÇ ve YÖNTEM}

\section{Hastalar}

Ocak 2010 ve Aralık 2017 tarihleri arasında merkezimizde mKRK tanısıyla takip edilen 427 hastanın verileri retrospektif olarak tarand. Metastatik evrede iki basamak standart kemoterapi rejimi sonrasi progresyon nedeniyle üçüncü basamakta oksaliplatin ya da irinotekan bazlı rejimlerle rechallenge tedavi ile regorafenib alan hastalar çalışmaya alındı.

Dahil etme kriterleri; 18 yaş ve üstü, histolojik olarak kanıtlanmış kolorektal karsinomu olmas1, Eastern Cooperative Oncology Group (ECOG) performans durumunun en fazla 2 olmas1, Response Evaluation Criteria in Solid Tumors (RECIST) kriterlerine göre ölçülebilir metastatik hastalık olmas1, daha önce metastatik evrede 5-FU, oksaliplatin ve irinotekan almış olmak ve yeterli karaciğer, kemik iliği ve böbrek fonksiyonuna sahip olmak. Dahil edilme kriterlerini karşılamayanlara ek olarak beyin metastazı olanlar çalışma dışı bırakıldı.

Hasta dosyalarından yaş, cinsiyet, ECOG performans durumu, vücut kitle indeksi (VKI), KRAS mutasyon durumu, tümör lokalizasyonu, metastatik hastalık süreleri, metastatik bölge sayısı, metastatik bölge lokalizasyonu, daha önce cerrahi yapılıp yapılmadığ kayıt edildi. Toksisite verileri yetersiz olduğundan toksisite analizi yapılamadı.

\section{Prosedür}

Rechallenge grubundaki hastalardan FOLFOX rejimini alan hastalara FA $400 \mathrm{mg} / \mathrm{m}^{2}$, 5-FU $400 \mathrm{mg} / \mathrm{m}^{2}$ bolus ve $2400 \mathrm{mg} / \mathrm{m}^{2} 5$-FU 46 saat infüzyonu ile Oksaliplatin $85 \mathrm{mg} / \mathrm{m}^{2}$, kombinasyonu iki haftada bir verildi (13). 
FOLFIRI rejimini alan hastalarda ise irinotekan $180 \mathrm{mg} / \mathrm{m}^{2}$ dozunda olup, 5-FU ve FA doz ve uygulama şeması FOLFOX ile benzerdi (2). Bevasizumab $5 \mathrm{mg} / \mathrm{kg}$, setüksimab $500 \mathrm{mg} / \mathrm{m}^{2}$ ve panitumumab 6 $\mathrm{mg} / \mathrm{kg}$ dozunda 2 haftada bir kemoterapi rejimleriyle kombine edilerek uygulandi. Regorafenib alan hastalarda ise doz $120 \mathrm{mg}$ veya $160 \mathrm{mg} /$ gün olarak başlanmış ve her 28 günlük döngünün 1-21. günleri arasında, tolerabiliteye göre minimum $80 \mathrm{mg}-$ maksimum $160 \mathrm{mg}$ arasında titre edilerek kullandırılmıştır.

Rechallenge grubundaki hastalar daha önceki kullanım sonrası tedavisiz süre (TS) bakımından da alt gruplara ayrılıp ayrı bir analiz yapıldı. Cut-off olarak, bu konuda yapılmış olan en büyük havuz-analizinde 6 ay sınırı kullanıldığından biz de analizimizde kesme değeri olarak 6 ay kullandik (11).

Tüm hastalara ilk siklusta 2 haftada bir olmak üzere daha sonra ise her siklusun ilk gününde fizik muayene, hematolojik ve biyokimyasal değerlendirme yapıldı.

Tümör cevab1, RECIST v1.1 kriterlerine göre her 12 haftada bir bilgisayarlı tomografi veya PET/BT (pozitron emisyon tomografi/ bilgisayarlı tomografi) ile değerlendirildi.

\section{Prognostik faktör analizi}

Daha önce yapılmış olan çalışmalardan yola çıkarak GSK'a etkisi olabilecek 13 değişken seçildi. Değişkenler iki kategoriye ayrıldı; yaş ( $<65$ veya $\geq 65$ y1l), cinsiyet (erkek veya kadın), BMI $\left(<25 \mathrm{~kg} / \mathrm{m}^{2}\right.$ veya $\left.\geq 25 \mathrm{~kg} / \mathrm{m}^{2}\right)$, tümör lokalizasyonu (sağ veya sol, rektum veya kolon), histolojik alt tip (adenokarsinom veya müsinöz karsinom), KRAS mutasyon durumu (mutant veya wild), metastatik bölge sayısı (1 veya $\geq 2$ ), karaciğer metastazı (var veya yok), akciğer metastazı (var veya yok), periton metastazı (var veya yok), metastatik hastalık süresi ( $<18$ ay veya $\geq 18$ ay), adjuvan tedavi alma durumu (evet veya hayrr).

\section{Istatistiksel analiz}

Analizi yapılan tedavileri aldıkları gün ile ölüme veya son vizite kadar geçen süre GSK, hastalık progresyonu veya herhangi bir nedenle ölüme kadar geçen süre progresyonsuz sağkalım (PSK) olarak hesaplandı.

Çalışmada elde edilen bulgular değerlendirilirken istatistiksel analizler için
SPSS 22.0 programı kullanıld1. İki grup arasındaki özelliklerin faklılıkları Pearson kikare veya Fisher's exact testi ile analiz edildi. Sağkalım analizi Kaplan-Meier yöntemi ile analiz edildi. Sağkalım süreleri $\% 95$ güven aralığında (GA) belirlenmiştir. Çoklu değişkenli analizler için Cox regresyon testi kullanıldı. $\mathrm{p}<0.05$ olan değerler istatistiksel olarak anlamlı kabul edildi.

\section{BULGULAR}

Çalışmaya toplam 61 hasta dahil edildi. Rechallenge grubunda 40 hasta (erkek \%58, kadın \%42), regorafenib grubunda 21 hasta (erkek \%76, kadın \%24) vardı. Ortanca yaş her iki çalışma kolunda da 56 yıldı (aralık; 30-74). Metastatik hastalık süresi rechallenge grubunda daha fazlaydı (21.7 ay ve 14.1 ay, $\mathrm{p}=0.002$ ). Rechallenge grubundaki hastaların tamamına yakınında senkron metastaz var iken regorafenib grubunda bu oran daha düşüktü (sirasiyla; $\% 93$ ve $\% 67, p=0.01$ ). Adjuvan tedavi alma oranı regorafenib kolunda daha fazlayd 1 (\%5'e karş1 $\% 29, \mathrm{p}=0.01)$. Hastaların tümü önceki iki basamakta 5-FU, oksaliplatin ve irinotekan almıştı. Rechallenge grubundaki hastaların \%58'i, regorafenib kolundaki hastaların ise \%81'i Anti-VEGF tedavi almıştı. $\mathrm{Bu}$ oran Anti-EGFR tedavi için sırasıyla \%30 ve \%38 idi. Bazal hasta özellikleri Tablo 1'de verilmiştir.

Ortanca 7.1 (2.2-41.6) takip süresinde, rechallenge grubundaki hastalarda ortanca tedavi süresi 3.8 ay, regorafenib grubunda 2.9 ayd. Rechallenge grubunda yedi hasta FOLFOX, on dört hasta FOLFOX+bevasizumab, dört hasta FOLFOX+setüksimab, iki hasta FOLFOX+panitumumab, on hasta FOLFIRI+setüksimab, iki hasta FOLFIRI+panitumumab ve bir hasta FOLFIRI+bevasizumab almıştı. Regorafenib grubundaki on beş hasta $(\% 71) 120 \mathrm{mg} /$ gün, altı hasta (\%29) $160 \mathrm{mg} /$ gün olarak tedaviye başlad1, hastaların son aldıkları doza bakıldığında on üç hasta $120 \mathrm{mg} / \mathrm{gün}$, dört hasta $160 \mathrm{mg} /$ gün dört hasta ise $80 \mathrm{mg} /$ gün almışlardı.

Hiçbir hastamızda tam yanıt (TY) gözlenmez iken rechallenge grubunda kısmi yanit (KY) oranı $\% 17$, regorafenib kolunda ise $\% 5$ idi $(\mathrm{p}=0.2)$. Tümör yanıt oranları Tablo 2 'de verilmiştir. Ortanca GSK tüm hastalarda

Adress for correspondence: Uzm. Dr. Yakup Ergün, Ankara Numune Education And Research Hospital 06100 Ankara - Türkiye 
9.6 ayd1 (\%95 GA 5.8-13.3). Rechallenge grubunda ortanca GSK 9.6 ay (7.3-13.3) iken regorafenib grubunda 7 ay (1.9-17) olup 2.6 aylık fark istatistiksel olarak anlamlı değildi (Hazard Oranı (HR): 1.05; \%95 GA 0.5-2.1, $\mathrm{p}=0.9$ ) (Şekil 1). Ortanca PSK açısından da her iki grup arasında istatistiksel fark yoktu (sirasiyla; 4.7 ay vs 3.1 ay, HR: 1.45; \%95 GA 0.82-2.5, $\mathrm{p}=0.1$ ) (Şekil 2).

Rechallenge grubundaki hastaları daha önce bu rejim sonrası TS bakımından $<6$ ay ve $\geq 6$ ay diye ayırdığımızda ise; yirmi üç hastada TS 6 ayın altında, on yedi hastada ise TS 6 aydan fazlayd1. TS $<6$ ay olan hastalarda bu rejimin tekrar denenmesinin sebebi çoğu hastanın (\%80) ilk kullanımlarında biyolojik ajan almamalarıdır. Üçüncü basamakta fazla seçenek olmamasından dolayı hedefe yönelik biyolojik ajan ile kombine halde tekrar bu rejimler denenmiştir. TS $\geq 6$ ay olan grupta ortanca PSK (sirasiyla 6.7 ay vs 4 ay, $p=0.4$ ) ve GSK (10.3 vs 7.1 ay, $\mathrm{p}=0.1)$ açisından numerik olarak fark olsa da bu fark istatistiksel olarak anlamlı değildi. TS'ye göre hasta özellikleri ve sonuçlar tablo 3 'te verilmiştir. Rechallenge grubundaki hastalardan TS $\geq 6$ ay olan hastalar ile regorafenib alan hastaları ortanca GSK (sırasıyla 10.3 ay' a karş1 7 ay, HR: 0.88; \%95 GA 0.42-1.8, p=0.8) ve PSK (sırasıyla 6.7 ay'a karşı 4 ay, HR: 1.83; \%95 GA 0.92-3.6, $\quad \mathrm{p}=0.08$ ) açısından karşılaştırdığımızda da anlamlı fark bulamadık. Genel sağ kalımı etkileyen prognostik faktörler tek değişkenli analizle değerlendirildiğinde; tümör lokalizasyonun sol tarafta olması (11.3 ay'a karşı 6.6 ay, p=0.03), metastatik bölge sayısının tek olması (14.5 ay'a karşı 7 ay, $\mathrm{p}=0.02$ ) ve akciğer metastazının olmaması (14.2 ay'a karş1 6.9 ay, $\mathrm{p}=0.01$ ) iyi prognostik faktörlerken, Cox-regresyon analizindeyse sadece metastatik bölge sayısının tek olmasının bağımsız prognostik faktör olduğu saptand (HR: 0.29; \%95 GA 0.11-0.77, p=0.01). Tek ve çok değişkenli analiz sonuçları Tablo 4'te verilmiştir.

Tablo 1. Hasta özellikleri

\begin{tabular}{ccccc}
\hline Özellik & Rechallenge & Regorafenib & Toplam & $\begin{array}{c}\text { p- } \\
\text { değeri }\end{array}$ \\
$\begin{array}{c}\text { Yaş (y1) } \\
\text { Ortanca } \\
\text { (aralık) } \\
<65\end{array}$ & $56(34-74)$ & $56(35-74)$ & N: $\mathbf{6 1}$ & 56 \\
& $32(\% 80)$ & $17(\% 81)$ & $\begin{array}{c}(34-74) \\
49\end{array}$ & \\
$\geq 65$ & $8(\% 20)$ & $4(\% 19)$ & $\begin{array}{c}\% 80) \\
12\end{array}$ & \\
\hline
\end{tabular}

\begin{tabular}{|c|c|c|c|c|}
\hline & & & $(\% 20)$ & \\
\hline Cinsiyet & & & & 0.1 \\
\hline Kadın & $17(\% 42)$ & $5(\% 24)$ & $\begin{array}{c}22 \\
(\% 36)\end{array}$ & \\
\hline Erkek & $23(\% 58)$ & $16(\% 76)$ & $\begin{array}{c}39 \\
(\% 64)\end{array}$ & \\
\hline $\begin{array}{l}\text { ECOG } \\
\text { performans } \\
\text { skoru }\end{array}$ & & & & 0.1 \\
\hline 0 & $10(\% 25)$ & $4(\% 19)$ & $\begin{array}{c}14 \\
(\% 23)\end{array}$ & \\
\hline 1 & $28(\% 70)$ & $15(\% 71)$ & $\begin{array}{c}43 \\
(\% 70)\end{array}$ & \\
\hline 2 & $2(\% 5)$ & $2(\% 10)$ & $4(\% 7)$ & \\
\hline $\begin{array}{l}\mathrm{VKİ}\left(\mathrm{kg} / \mathrm{m}^{2}\right) \\
<25\end{array}$ & $20(\% 50)$ & $15(\% 71)$ & 35 & 0.1 \\
\hline$\geq 25$ & $20(\% 50)$ & $6(\% 29)$ & $\begin{array}{c}(\% 57) \\
16 \\
(\% 43)\end{array}$ & \\
\hline $\begin{array}{l}\text { Tümör } \\
\text { lokalizasyonu-1 }\end{array}$ & & & & 0.6 \\
\hline Kolon & $24(\% 60)$ & $14(\% 67)$ & $\begin{array}{c}38 \\
(\% 62)\end{array}$ & \\
\hline Rektum & $16(\% 40)$ & $7(\% 33)$ & $\begin{array}{c}23 \\
(\% 38)\end{array}$ & \\
\hline $\begin{array}{l}\text { Tümör } \\
\text { lokalizasyonu-2 }\end{array}$ & & & & 0.2 \\
\hline Sol & $29(\% 72)$ & $18(\% 86)$ & $\begin{array}{c}47 \\
(\% 77)\end{array}$ & \\
\hline Sağ & $11(\% 28)$ & $3(\% 14)$ & $\begin{array}{c}14 \\
(\% 23)\end{array}$ & \\
\hline $\begin{array}{l}\text { Histopatolojik } \\
\text { alt tip }\end{array}$ & & & & 0.9 \\
\hline Adenokarsinom & $36(\% 90)$ & $19(\% 90)$ & $\begin{array}{c}55 \\
(\% 90)\end{array}$ & \\
\hline $\begin{array}{l}\text { Müsinöz } \\
\text { Karsinom }\end{array}$ & $4(\% 10)$ & $2(\% 10)$ & $6(\% 10)$ & \\
\hline KRAS & & & & 0.1 \\
\hline Mutant & $12(\% 30)$ & $10(\% 48)$ & $\begin{array}{c}22 \\
(\% 36)\end{array}$ & \\
\hline Wild & $28(\% 70)$ & $11(\% 52)$ & $\begin{array}{c}39 \\
(\% 64)\end{array}$ & \\
\hline $\begin{array}{l}\text { Metastatik } \\
\text { bölge sayıs1 }\end{array}$ & & & & 0.08 \\
\hline 1 & $14(\% 35)$ & $3(\% 14)$ & $\begin{array}{c}17 \\
(\% 28)\end{array}$ & \\
\hline$\geq 2$ & $26(\% 65)$ & $18(\% 86)$ & $\begin{array}{c}44 \\
(\% 72)\end{array}$ & \\
\hline \multicolumn{5}{|l|}{$\begin{array}{l}\text { Metastatik } \\
\text { bölge }\end{array}$} \\
\hline Karaciğer & $31(\% 78)$ & $17(\% 81)$ & $\begin{array}{c}48 \\
(\% 79)\end{array}$ & 0.7 \\
\hline Akciğer & $22(\% 55)$ & $10(\% 48)$ & $\begin{array}{c}32 \\
(\% 54)\end{array}$ & 0.5 \\
\hline Periton & $13(\% 33)$ & $8(\% 38)$ & $\begin{array}{c}21 \\
(\% 34)\end{array}$ & 0.7 \\
\hline $\begin{array}{l}\quad \text { Kemik } \\
\text { Metastatik } \\
\text { hastalık süresi } \\
\text { (ay) }\end{array}$ & $4(\% 10)$ & $1(\% 5)$ & $6(\% 8)$ & $\begin{array}{c}0.4 \\
\mathbf{0 . 0 0 2}\end{array}$ \\
\hline $\begin{array}{l}\text { Ortanca } \\
\text { (aralık) }\end{array}$ & $21.7(7-67)$ & $\begin{array}{c}14.1 \\
(6.1-36.7)\end{array}$ & $\begin{array}{c}20.1 \\
(6.1-67)\end{array}$ & \\
\hline$<18$ ay & $10(\% 25)$ & $14(\% 67)$ & $\begin{array}{c}24 \\
(\% 39)\end{array}$ & \\
\hline$\geq 18$ ay & $30(\% 75)$ & $7(\% 33)$ & $\begin{array}{c}37 \\
(\% 61)\end{array}$ & \\
\hline \multicolumn{5}{|l|}{$\begin{array}{l}\text { Daha önce } \\
\text { kullanilan ajan }\end{array}$} \\
\hline Fluoroprimidin & $40(\% 100)$ & $21(\% 100)$ & $\begin{array}{c}61 \\
(\% 100)\end{array}$ & \\
\hline Oksaliplatin & $40(\% 100)$ & $21(\% 100)$ & $\begin{array}{c}61 \\
(\% 100)\end{array}$ & \\
\hline İrinotekan & $40(\% 100)$ & $21(\% 100)$ & $\begin{array}{c}61 \\
(\% 100)\end{array}$ & \\
\hline
\end{tabular}




\begin{tabular}{|c|c|c|c|}
\hline $\begin{array}{l}\text { Anti-VEGF } \\
\text { ajan }\end{array}$ & $23(\% 58)$ & $17(\% 81)$ & $\begin{array}{c}40 \\
(\% 66)\end{array}$ \\
\hline $\begin{array}{l}\text { Anti-EGFR } \\
\text { ajan }\end{array}$ & $12(\% 30)$ & $8(\% 38)$ & $\begin{array}{c}21 \\
(\% 34)\end{array}$ \\
\hline \multicolumn{4}{|l|}{$\begin{array}{l}\text { Metastaz } \\
\text { durumu }\end{array}$} \\
\hline Senkron & $37(\% 93)$ & $14(\% 67)$ & $\begin{array}{c}51 \\
(\% 84)\end{array}$ \\
\hline Metakron & $3(\% 7)$ & $7(\% 33)$ & $\begin{array}{c}10 \\
(\% 16)\end{array}$ \\
\hline \multicolumn{4}{|l|}{$\begin{array}{l}\text { Adjuvan } \\
\text { kemoterapi } \\
\text { öyküsü }\end{array}$} \\
\hline Hayır & $38(\% 95)$ & $15(\% 71)$ & $\begin{array}{c}53 \\
(\% 87)\end{array}$ \\
\hline Evet & $2(\% 5)$ & $6(\% 29)$ & $8(\% 13)$ \\
\hline
\end{tabular}

$\mathbf{0 . 0 1}$

0.01

ECOG=Eastern Cooperative Oncology Group, VKİ=Vücut Kitle İndeksi VEGF=Vasküler Endotelyal Büyüme Faktör, EGFR $=$ Epidermal Büyüme Faktör Reseptorü

Tablo 2. Tümör yanıt oran1

\begin{tabular}{|c|c|c|c|}
\hline & Rechallenge & Regorafenib & $\begin{array}{c}\text { p- } \\
\text { değeri }\end{array}$ \\
\hline & n: 40 & n: 21 & \\
\hline $\begin{array}{l}\text { Tam yanit } \\
\text { (TY) }\end{array}$ & 0 & 0 & - \\
\hline $\begin{array}{l}\text { Kismi yanit } \\
(\mathrm{KY})\end{array}$ & $7(\% 17)$ & $1(\% 5)$ & 0.24 \\
\hline $\begin{array}{l}\text { Stabil } \\
\text { hastalık } \\
(\mathrm{SH})\end{array}$ & $7(\% 17)$ & $3(\% 14)$ & - \\
\hline $\begin{array}{l}\text { Progresif } \\
\text { hastalık } \\
(\mathrm{PH})\end{array}$ & $26(\% 65)$ & $17(\% 81)$ & 0.19 \\
\hline $\begin{array}{l}\text { Objektif } \\
\text { yanit oranı }\end{array}$ & $\% 17$ & $\% 5$ & 0.24 \\
\hline $\begin{array}{l}\text { Hastalık } \\
\text { kontrol } \\
\text { oran1 }\end{array}$ & $\% 35$ & $\% 19$ & 0.19 \\
\hline
\end{tabular}

Tablo 3. Rechallenge grubunda tedavisiz süreye göre etkinlik ve hasta özellikleri

\begin{tabular}{|l|c|c|}
\hline & $\begin{array}{c}<6 \text { ay (n: } \\
\mathbf{2 3})\end{array}$ & $\begin{array}{c}\geq \mathbf{6} \text { ay (n: } \\
\mathbf{1 7})\end{array}$ \\
\hline TS, ortanca ay (aralık) & $\begin{array}{c}1.9 \\
(0.1-5.6)\end{array}$ & $\begin{array}{c}12 \\
(6-46.3)\end{array}$ \\
\hline $\begin{array}{l}\text { İlk kullanım PSK, ortanca } \\
\text { ay }\end{array}$ & 7.3 & 12 \\
\hline Rechallenge sonrası PSK & 4 & 6.7 \\
\hline Rechallenge sonras1 GSK & 7.1 & 10.3 \\
\hline $\begin{array}{l}\text { İlk kullanım tümör yanıt } \\
\text { oranı }\end{array}$ & & \\
\hline Tam yanıt & 0 & $3(\% 18)$ \\
\hline Kismi yanıt & $13(\% 57)$ & $6(\% 35)$ \\
\hline Stabil hastalık & $8(\% 30)$ & $7(\% 47)$ \\
\hline Progresif hastalık & $3(\% 13)$ & 0 \\
\hline Objektif yanıt oran1 & $\% 57$ & $\% 53$ \\
\hline $\begin{array}{l}\text { Rechallenge sonrası tümör } \\
\text { yanıt oranı }\end{array}$ & & \\
\hline Tam yanıt & $3(\% 13)$ & $4(\% 23)$ \\
\hline Kismi yanıt & $3(\% 13)$ & $4(\% 23)$ \\
\hline Stabil hastalık & $17(\% 74)$ & $9(\% 53)$ \\
\hline Progresif hastalık
\end{tabular}

\begin{tabular}{|c|c|c|}
\hline Objektif yanıt oranı & $\% 13$ & $\% 23$ \\
\hline Rechallenge yapılan rejim & & \\
\hline FOLFOX & $15(\% 65)$ & $13(\% 77)$ \\
\hline FOLFIRI & $8(\% 35)$ & $4(\% 23)$ \\
\hline
\end{tabular}

$\mathrm{TS}=$ Tedavisiz süre; $\mathrm{PSK}=$ Progresyonsuz sağ kalım; GSK=Genel sağ kalım; FOLFOX= 5-Fluorourasil, folinik asit ve oxaliplatin; FOLFIRI=5-Fluorourasil, folinik asit ve irinotekan

Tablo 4. Genel sağ kalım için tek değişkenli ve çok değişkenli analiz sonuçları

\begin{tabular}{|c|c|c|c|}
\hline Değişken & $\begin{array}{c}\text { GSK için tek } \\
\text { değişkenli } \\
\text { analiz, ortanca } \\
\text { (ay) }\end{array}$ & $\begin{array}{l}\text { p- } \\
\text { değeri }\end{array}$ & $\begin{array}{c}\text { Çok değişkenli } \\
\text { analiz }\end{array}$ \\
\hline \multicolumn{4}{|l|}{ Yaş } \\
\hline$<65$ y1l & 10.3 & 0.5 & \\
\hline$\geq 65 \mathrm{y} 1 \mathrm{l}$ & 6.9 & & \\
\hline \multicolumn{4}{|l|}{ Cinsiyet } \\
\hline Kadın & 10.2 & 0.1 & $\begin{array}{c}\mathrm{HR}=0.47, \% 95 \\
\mathrm{GA} 0.20-1.09 \\
\mathrm{p}=0.08\end{array}$ \\
\hline Erkek & 7.4 & & \\
\hline \multicolumn{4}{|l|}{ VKİ $\left(\mathrm{kg} / \mathrm{m}^{2}\right)$} \\
\hline$<25$ & 9.6 & 0.9 & \\
\hline$\geq 25$ & 8.5 & & \\
\hline \multicolumn{4}{|l|}{$\begin{array}{l}\text { Tümör } \\
\text { lokalizasyonu-1 }\end{array}$} \\
\hline Kolon & 10.6 & 0.9 & \\
\hline Rektum & 7.1 & & \\
\hline \multicolumn{4}{|l|}{$\begin{array}{l}\text { Tümör } \\
\text { lokalizasyonu-2 }\end{array}$} \\
\hline Sol & 11.3 & 0.03 & $\begin{array}{c}\mathrm{HR}=0.86, \% 95 \\
\mathrm{GA} 0.36-2.01, \\
\mathrm{p}=0.7\end{array}$ \\
\hline Sağ & 6.6 & & \\
\hline \multicolumn{4}{|l|}{$\begin{array}{l}\text { Histopatolojik } \\
\text { alt tip }\end{array}$} \\
\hline Adenokarsinom & 10.2 & 0.1 & $\begin{array}{c}\mathrm{HR}=0.39, \% 95 \\
\text { GA } 0.12-1.24 \\
\mathrm{p}=0.1\end{array}$ \\
\hline $\begin{array}{c}\text { Müsinöz } \\
\text { Karsinom }\end{array}$ & 6.5 & & \\
\hline \multicolumn{4}{|l|}{ KRAS } \\
\hline Mutant & 11.6 & 0.1 & $\begin{array}{c}\mathrm{HR}=1.20, \% 95 \\
\mathrm{GA} 0.60-2.41 \\
\mathrm{p}=0.5\end{array}$ \\
\hline Wild & 7.1 & & \\
\hline \multicolumn{4}{|l|}{$\begin{array}{l}\text { Metastatik } \\
\text { bölge sayıs1 }\end{array}$} \\
\hline 1 & 14.5 & 0.02 & $\begin{array}{c}\text { HR=0.29, \%95 } \\
\text { GA } 0.11-0.77, \\
\text { p=0.01 }\end{array}$ \\
\hline$\geq 2$ & 7.0 & & \\
\hline \multicolumn{4}{|l|}{$\begin{array}{l}\text { Metastatik } \\
\text { bölge }\end{array}$} \\
\hline $\begin{array}{r}\text { Karaciğer } \\
\text { (Evet/Hayır) }\end{array}$ & $8.7 / 14.2$ & 0.3 & \\
\hline $\begin{array}{c}\text { Akciğer } \\
\text { (Evet/Hayır) }\end{array}$ & $6.9 / 14.2$ & 0.01 & $\begin{array}{c}\mathrm{HR}=1.22, \% 95 \\
\mathrm{GA} 0.51-2.90 \\
\mathrm{p}=0.6\end{array}$ \\
\hline $\begin{array}{c}\text { Periton } \\
\text { (Evet/Hayır) }\end{array}$ & $7.4 / 10.2$ & 0.6 & \\
\hline
\end{tabular}

Adress for correspondence: Uzm. Dr. Yakup Ergün, Ankara Numune Education And Research Hospital 06100 Ankara - Türkiye e-mail: dr.yakupergun@gmail.com 


\begin{tabular}{|c|c|c|c|}
\hline $\begin{array}{l}\text { Metastatik } \\
\text { hastalık süresi }\end{array}$ & 7.0 & 0.1 & $\begin{array}{c}\mathrm{HR}=0.94, \% 95 \\
\mathrm{GA} 0.43-2.03, \\
\mathrm{p}=0.8\end{array}$ \\
\hline$<18$ ay & 10.2 & & \\
\hline$\geq 18$ ay & & & \\
\hline $\begin{array}{l}\text { Adjuvan } \\
\text { kemoterapi } \\
\text { öyüsü }\end{array}$ & & & \\
\hline Evet & 11.3 & 0.7 & \\
\hline Hayır & 9.6 & & \\
\hline
\end{tabular}

GSK=Genel sağ kalım, VKİ=Vücut kitle indeksi, , HR= Hazard oran1, GA=Güven aralı̆̆

Şekil 1. Genel sağkalım için Kaplan-Meier sağkalım eğrisi

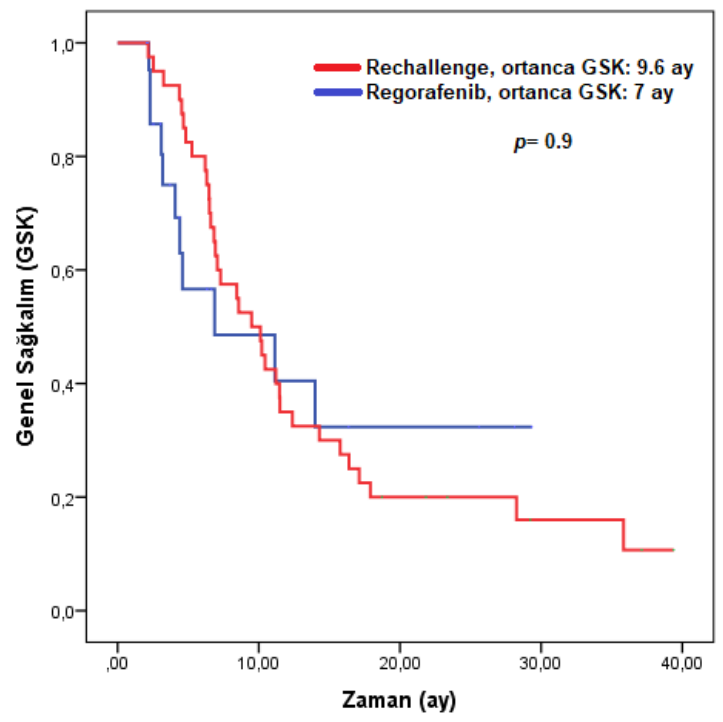

Şekil 2. Progresyonsuz sağkalım için KaplanMeier sağkalım eğrisi

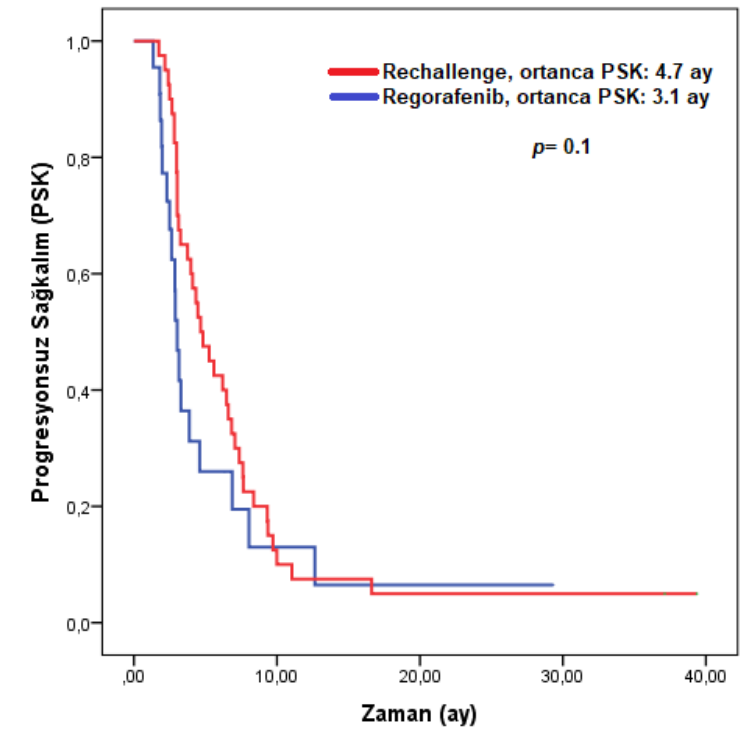

Tartışma
Çalışmamızda iki basamak standart tedavi alıp progresyon gösteren mKRK tanılı hastalarda oksaliplatin ya da irinotekan temelli rechallenge kemoterapileri ile regorafenib arasinda ortanca PSK ve GSK farkı bulunmadı. $\mathrm{Bu}$ hasta grubunda yapılmış olan üç farklı faz3 çalışmada da ortanca GSK, tedavi kollarında plaseboya oranla daha iyi bulunmuştur (CORRECT çalışmasında regorafenib ile 6.4 ay, CONCUR çalışmasında regarofenib ile 8.8 ay ve RECOURSE çalışmasında TAS-102 ile 7.1 ay) (7-9). REBECCA kohortu olarak bilinen ve 656 hastanın değerlendirildiği (14) çalışmada regorafenib ile ortanca GSK 5.6 ay olarak bildirilmiştir. Yukarıdaki tüm çalışmalarda ortanca PSK 1.9 ay ile 3.2 ay arasındadır. $\mathrm{Bu}$ verilere göre, bizim çalışmamızdaki regorafenib ile elde edilen sağkalım sürelerinin literatür ile uyumlu olduğu söylenebilir.

Oksaliplatin veya irinotekan rechallenge ile ilgili yapılan çalışmalara baktığımızda ise; 2004 yılında 29 hasta ile yapılan retrospektif bir çalışmada (15) FOLFOX rechallenge yapılan hastalarda ortanca PSK 4.2 ay ve ortanca GSK 9.8 ay olarak bildirildi. $\mathrm{Bu}$ çalışmanın ardından periferal sensorinoral noropati insidansin1 azalatmak için bekle-izle-tekrar başla stratejisine göre oksaliplatinsiz bir dönemden sonra tekrar oksaliplatin verilmesinin incelendiği OPTIMOX1 (16) ve OPTIMOX2 (17) prospektif çalışmaları yapıldı. OPTIMOX1 çalıșmasında 6 kür FOLFOX alan hastalar FUFA idame ve FOLFOX idame kollarına ayrıldığında PSK ve GSK'de fark saptanmamıştır. OPTIMOX2 çalışmasında ise tedavi bir kolda 6 kür FOLFOX kemotereapisi sonrası tedavi tamamen kesilip tümör eski boyutlarına gelince yeniden başlanmış, diğer kolda ise OPTIMOX1 deki idame kolundaki hastalara progresyonda FOLFOX tekrar başlanarak incelenmiştir ve bu çalışmada, FUFA idamesinin PS ve GSK'1 uzattığ görülmüştür. Oksaliplatin tedavisinden sonra progresyon görülen hastalarda oksaliplatin rechallenge yapılan ilk prospektif çalışma olan faz-2 RE-OPEN (12) çalışmasında ise ortanca GSK 10 ay olarak bildirildi. Çalışmamıza benzer olarak yapılmış olan standart iki basamak tedavi sonrasi FOLFOX+bevasizumab veya FOLFIRI+bevasizumab rechallenge tedavisinin etkinliğinin değerlendirildiği 
retrospektif bir çalışmada ortanca PSK 5.3 ay ve ortanca GSK 9.5 ay olarak bildirilmiştir (18). Yine çalışmamıza benzer olarak dizayn edilmiş olan diğer bir retrospektif çalışmada ortanca PSK 6 ay, GSK 10 ay olarak bildirilmiştir (19). Bu verilere bakıldığında rechallenge grubundaki hastalarımızın ortanca PSK ve GSK sonuçlarının literatür ile uyumlu olduğu görülmektedir.

Çalışmamızın bir diğer sonucunda, rechallenge grubunda oksaliplatin veya irinotekansız sürenin (TS) 6 aydan kısa veya uzun olmasının sağ kalıma etkisiydi. Biz de over kanserinde ki platine duyarlılık ölçütü olan 6 aylik cut-off değerini (20), OPTIMOX çalışmalarının ortak analizindeki (11) cut-off değerinin de 6 ay olarak seçilmesinden dolayı rechallenge grubundaki hastalarımızı iki gruba ayırmada kullandık. Çalışmamızda TS $\geq 6$ ay olan grupta ortanca PSK ve GSK numerik olarak daha iyi olsa da bu fark istatistiksel anlamlılığa ulaşamadı (PSK için sırasıyla; 6.7 ay'a karşı 4 ay, p=0.4, GSK için 10.3 ay'a karş1 7.1 ay, $\mathrm{p}=0.1$ ). İstatistiksel anlamlılığa ulaşmamasının sebebi hasta sayımızın az olması olabilir. Bu cut-off değerini kullanarak yapılan OPTIMOX çalışmalarının ortak analizinde TS $<6$ ay olan grupta ortanca PSK 5.5 ay ve ortanca GSK 14.3 ay, TS $\geq 6$ ay olan grupta ise sirasıyla 5.5 ay'a karşı 16.8 ay olarak bildirildi. Cut-off değerinin 12 ay olarak alındığı bir diğer oksaliplatin rechallenge çalışmasında (21) ise TS <12 ay olan grupta ortanca PSK 3 ay ve ortanca GSK 8 ay, TS $\geq 12$ ay olan grupta ise sirasiyla 9 ay ve 21.7 ay olarak bildirildi. Her iki çalışmada da tedavisiz sürenin uzun olmasının daha iyi sağkalım ile sonuçlandığı görülmektedir. Biz çalışmamızda ortanca sağ kalımları daha kısa olarak bulduk. Bunun gerekçesinin, bizim hasta popülasyonumuzun kemorefrakter hasta grubu olmasından kaynaklandığını düşünüyoruz.

Çalışmamızda TS $\geq 6$ ay olan rechallenge grubunda ortanca PSK ve GSK regorafenibe göre numerik olarak daha uzun olsa da bu farkı istatistiksel anlamlı bulmadık. TS $<6$ ay olan grupta ki hastalarımızın çoğu (\%80) ilk tedavilerinde biyolojik ajan almamışlardı. Biyolojik ajan kombinasyonu ile rechallenge yapıldığında bu hasta grubunda bile PSK ve GSK sonuçları regorafenib ile benzer olduğu görülmekte. TS $<6$ ay olan grupta regorafenibe benzer etkinin biyolojik ajan eklenmesinden dolayı olduğunu kesin olarak söyleyemiyoruz, ancak daha önce yapılmış çalışmalarda bevasizumab ve setüksimab ile rechallenge tedaviyle sağkalım faydası gösterilmiştir $(19,22)$. Çalışmamızda ki sonuçlara dayanarak TS $\geq 6$ ay olan hastalar ile TS $<6$ ay olsa bile ve özellikle daha önce biyolojik ajan almamışsa rechallenge tedavinin regorafenib ile benzer etkinlikte olduğu görülmektedir. Kemorefrakter mKRK tanılı hastalarımızda hem rechallenge ile tedavi hem de regorafenib ile sağkalım verilerimizin çoğu literatür verisi ile uyumlu olduğundan yaptığımız çalışmanın onkoloji pratiğinde anlamlı yer edineceğini düşünüyoruz.

Çalışmamızın bazı kısıtlamalar mevcuttu. Çalışmamızın retrospektif olması, örneklem sayısının küçüklügü ve rechallenge grubundaki tedavilerin heterojenliği çalışmamızın gücünü sınırlamaktadır. Bir diğer önemli limitasyonumuz ise toksisite verilerine ulaşılamamış olmasıdır. Önemli pozitif yönleri ise gerçek yaşam verisi olması ve rechallenge tedavi ile regorafenibin karşılaştırıldığı ilk çalışma olmasıdır.

Sonuç olarak; bu çalışma metastatik kolorektal kanserli hastalarda üçüncü basamakta oksaliplatin ya da irinotekan bazlı rechallenge kemoterapi ile regorafenibi karşılaştıran ilk çalışmadır. Günümüzde bu hasta grubu için regorafenib, TAS-102 ve bazı seçilmiş hasta gruplarında Anti PD-1 ajanlar önerilmektedir. Ancak her ülkede bu ilaçlara erişim mümkün olmamakta, ulaşılsa bile bu tedaviler ile progrese olan hastalarda uygulanabilecek tedavi seçenekleri net değildir. Sonuçlarımıza göre rechallenge tedavi ile regorafenib benzer etkinliktedir. Çalışma sonuçlarımıza dayanarak performans durumu iyi olan metastatik kolorektal kanserli hastaların üçüncü basamak tedavisinde rechallenge tedavi alternatif bir tedavi seçeneği veya kılavuzların önerdiği tedaviler ile progrese olan hastalarda sonraki basamaklarda tercih edilebilecek bir seçenek olabilir. . Ancak hasta sayımızın azlığı ve çalışmamızın retrospektif olması nedeniyle bu konuda çok sayıda hasta içeren prospektif çalışmalara ihtiyaç vardır.

\section{Çıkar Çatışması: Yok}




\section{REFERANSLAR}

1. 1. Heinemann V, von Weikersthal LF, Decker T et al. FOLFIRI plus cetuximab versus FOLFIRI plus bevacizumab as first-line treatment for patients with metastatic colorectal cancer (FIRE-3): a randomised, open-label, phase 3 trial. Lancet Oncol. 2014;15(10):1065-75.

2. National Comprehensive Cancer Network. NCCN Clinical Practice Guidelines in Oncology: Colon Cancer. March 14, 2018 - Version 2.2018

3. Van Cutsem E, Cervantes A, Adam R, et al. ESMO consensus guidelines for the management of patients with metastatic colorectal cancer. Ann Oncol. 2016;27(8):1386-422.

4. Tournigand C, André T, Achille E et al. FOLFIRI followed by FOLFOX6 or the reverse sequence in advanced colorectal cancer: a randomized GERCOR study. J Clin Oncol. 2004;22(2):229-37.

5. Jonker DJ, O'Callaghan CJ, Karapetis CS, et al. Cetuximab for the treatment of colorectal cancer. N Engl J Med. 2007;357(20):2040-8.

6. Van Cutsem E, Peeters M, Siena S, et al. Open-label phase III trial of panitumumab plus best supportive care compared with best supportive care alone in patients with chemotherapy-refractory metastatic colorectal cancer. J Clin Oncol. 2007;25(13):165864.

7. Grothey A, Van Cutsem E, Sobrero A, et al. Regorafenib monotherapy for previously treated metastatic colorectal cancer (CORRECT): an international, multicentre, randomized, placebo controlled, phase 3 trial. Lancet. 2013; 381(9863): 303-12.

8. Li J, Qin S, Xu R, Yau TCC, et al. Regorafenib plus best supportive care versus placebo plus best supportive care in Asian patients with previously treated metastatic colorectal cancer (CONCUR): a randomized, double-blind, placebo-controlled, phase 3 trial. Lancet Oncol. 2015;16(6):619-29.

9. Mayer RJ, Van Cutsem E, Falcone A, et al. Randomized trial of TAS-102 for refractory metastatic colorectal cancer. N Engl J Med. 2015;372:1909-19.

10. Wilhelm SM, Dumas J, Adnane L, et al. Regorafenib (BAY 73-4506): a new oral multikinase inhibitor of angiogenic, stromal andoncogenic receptor tyrosine kinases with potent preclinical antitumor activity. Int J Cancer. 2011;129(1):24555 .

11. Chibaudel B, Tournigand $C$, Bonnetain F, et al. Platinum-sensitivity in metastatic colorectal cancer: towards a definition. Eur J Cancer. 2013; 49(18):3813-20.
12. Suenaga M, Mizunuma N, Matsusaka S, et al. Phase II study of reintroduction of oxaliplatin for advanced colorectal cancer in patients previously treated with oxaliplatin and irinotecan: RE-OPEN study. Drug Des Dev Ther. 2015; 9:3099-108.

13. Cheeseman SL, Joel SP, Chester JD, et al. A 'modified de Gramont' regimen of fluorouracil, alone and with oxaliplatin, for advanced colorectal cancer. Br J Cancer. 2002;87(4):393-9.

14. Adenis A, de la Fouchardiere C, Paule B, et al. Survival, safety, and prognostic factors for outcome with regorafenib in patients with metastatic colorectal cancer refractory to standard therapies: results from a multicenter study (REBACCA) nested within a compassionate use program. BMC Cancer. 2016;16:412.

15. Maindrault-Goebel $\mathrm{F}$, Tournigand $\mathrm{C}$, André $\mathrm{T}$, et al. Oxaliplatin reintroduction in patients previously treated with leucovorin, fluorouracil and oxaliplatin for metastatic colorectal cancer. Ann Oncol. 2004; 15(8):1210-4.

16. Tournigand $\mathrm{C}$, Cervantes $\mathrm{A}$, Figer $\mathrm{A}$, et al. OPTIMOX1: a randomized study of FOLFOX4 or FOLFOX7 with oxaliplatin in a stop-and-go fashion in advanced colorectal cancer - a GERCOR study. J Clin Oncol. 2006;24(3):394-400.

17. Chibaudel B, Maindrault-Goebel F, Lledo G, et al. Can chemotherapy be discontinued in unresectable metastatic colorectal cancer? The GERCOR OPTIMOX2 Study. J Clin Oncol. 2009;27(34):5727-33.

18. Kang BW, Kim TW, Lee JL, et al. Bevacizumab plus FOLFIRI or FOLFOX as third-line or later treatment in patients with metastatic colorectal cancer after failure of 5-fluorouracil, irinotecan, and oxaliplatin: a retrospective analysis. Med Oncol. 2009; 26(1):32-7.

19. Özaslan $E$, Bozkurt $O$, Duran $A O$, Uçar $M$, İnanç $M$, Özkan M. Rechallenge chemotherapy as a third line treatment option for metastatic colorectal carcinoma. Ortadogu Medical Journal. 2017; 9(4):163-9.

20. Pignata $S, C$ Cecere $S$, Du Bois A, Harter P, Heitz F. Treatment of recurrent ovarian cancer. Ann Oncol. 2017 1;28(suppl_8):viii51-viii56.

21. Kim JJ, Kang J, Hong YS, et al. Oxaliplatin rechallenge in metastatic colorectal cancer patients after prior oxaliplatin treatment. Med Oncol. 2018;35(5):65.

22. Ishiguro $M$, Watanabe $T$, Yamaguchi $K$, et al. A Japanese post-marketing surveillance of cetuximab $\left(\right.$ Erbitux $\left.^{(\mathrm{R})}\right)$ in patients with metastatic colorectal cancer. Jpn J Clin Oncol 2012;42(4):287-94. 